\title{
DESIGN OF A WORKSTATION TABLE WITH IMPROVED CRASHWORTHINESS
} PERFORMANCE

\author{
Daniel P. Parent \\ David C. Tyrell \\ Volpe National Transportation Systems Center \\ U.S. Department of Transportation \\ Cambridge, MA 02142
}

Robert Rancatore

TIAX, LLC

Cambridge, MA 02140

\section{ABSTRACT}

Work is currently underway to develop strategies to protect rail passengers seated at workstation tables during a collision or derailment. Investigations have shown that during a collision, these tables can present a hostile secondary impact environment to the occupants.

This effort includes the design, fabrication, and testing of an improved workstation table. The key criteria for the design of this table are that it must compartmentalize the occupants and reduce the risk of injury relative to currently installed tables. Strengthening the attachments between the table and the passenger car body will ensure compartmentalization. Employing energy-absorbing mechanisms to limit and distribute the load imparted on the abdomen of the occupant will reduce injury risk.

This paper details the design requirements for an improved workstation table, which include service, fabrication, and occupant protection requirements. Service requirements define the geometry of the table, the performance of the table under normal service loads, and the maintenance of the table over the period of installation. Fabrication requirements define the limitations on material usage and construction costs. Occupant protection requirements define the ability of the table to reduce injury risk to the occupants under collision loads. The table must also conform to federal regulations pertaining to interior structures on passenger rail equipment.

Four design concepts are evaluated against these design requirements. These concepts present different modes of deformation or displacement that absorb energy during impact. These concepts have been evaluated, and the highest-ranking concept involves a crushable foam or honeycomb table edge attached to a rigid center frame. Preliminary results from a computer simulation demonstrate the effectiveness of this concept in reducing the injury risk to the occupants.

\section{INTRODUCTION}

The Volpe Center has been supporting the Equipment Safety Research Program of the Federal Railroad Administration (FRA) in performing rail passenger equipment crashworthiness research. The overall objective of this research has been to develop strategies for incrementally improving structural crashworthiness and occupant protection. The structural crashworthiness research involves the modification of passenger rail equipment to preserve the occupant volume [1]. Preservation of the occupant volume is a necessity for preventing life-threatening injuries in rail collisions. Once the occupant volume is preserved, further strategies can be implemented to reduce injury risk.

As part of this effort, a field study of occupant injuries during rail collisions and derailments is currently being conducted. The objectives of this study are to determine the range of severity of the injuries that occur in train collisions and derailments, the types of injuries that occur, where these injuries occur on the train, and the causal mechanisms for these injuries. This information is used to identify the areas where occupant protection strategies can reduce the risk of injury.

One of the collisions investigated as part of this field study occurred in Placentia, CA, on April 23, 2002. A standing passenger train was impacted by a freight train approaching on the same track. The nature of the deformation of the impacted cab car resulted in a severe occupant environment to the occupants seated forward of the rear stairwell of the cab car [2]. There were over 260 injuries, including 143 transported to medical facilities, 22 serious, and 2 fatal [3]. The two fatally injured passengers, as well as several seriously injured passengers, were seated in facing-seat configurations with intervening workstation tables. Analysis of this collision indicated that the application of occupant protection strategies could reduce the risk of injury to occupants seated at workstation tables [2].

Two workstation table experiments were included on the two-car full-scale impact test of Crash Energy Management 
(CEM) equipment. The objectives of this test were to demonstrate the ability of the CEM passenger equipment to preserve the occupied volume of the cars and to share structural crush with the trailing car in a coupled-car arrangement [4]. The results of these experiments confirmed the need to develop occupant protection strategies for this seating arrangement. The occupant protection strategy suggested by the results of this test has two necessary elements. The first is that the table must remain firmly attached to the car body to compartmentalize the occupants, independent of the number and mass of the occupants seated at the table. The second element is that the table must limit the load imparted on the upper abdomen of the occupants. A computer simulation refined after the full-scale test was used to demonstrate that a table that fulfills both of these elements could significantly reduce the thoracic and abdominal injury risk to occupants seated at the table during a collision [5].

Work is currently underway to design, fabricate, and test an improved workstation table that will mitigate the risk of thoracic and abdominal injury during rail collisions. While the scope of this effort is limited to workstation tables, this work can eventually be applied to both dining and lounge tables as well. This paper covers the design requirements, concept generation and evaluation process, and the preliminary design concept that will be fabricated and tested.

\section{DEVELOPMENT STRATEGY}

Figure 1 depicts the strategy for the development of an improved workstation table, which involves six steps. A similar strategy is followed in the development of an optimized commuter seat for passenger rail vehicles [6]. Extensive work on the first two steps is reported in Reference [2]. Corresponding detail on steps three and four is described in Reference [5]. This paper concentrates on the fifth step in the process. It is anticipated that the sixth step, testing of the tables, will be carried out on the train-to-train full-scale impact test of CEM equipment planned for February 2006.

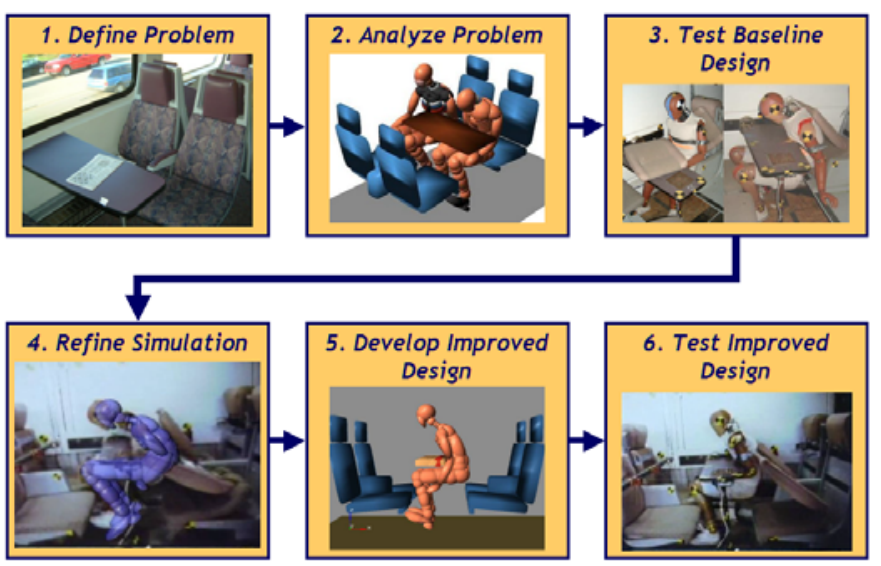

Figure 1. Strategy for the development of an improved workstation table.

\section{Define the Problem}

The first step in the development process involves a historical review of workstation table-related injuries, an examination of the data collected as part of the field study described above, and a survey of existing workstation table designs. The information collected is used to determine the causal mechanisms for injury, which in turn dictate the areas where improvement is necessary. During the Placentia, CA, collision, impact with workstation tables brought about severe thoracic and abdominal injuries. These injuries consisted of liver and spleen lacerations, fractured ribs, heart contusions, and vertebral fractures in the most severe cases [2]. The likely cause of these injuries is blunt trauma to the upper abdomen due to secondary impact with the tables. In addition to the thoracic and abdominal injuries, several occupants sustained head injuries from impact of the face with the tabletop at the point of maximum abdominal penetration. It is also likely that at least one of the tables failed in such a way that the occupant was thrown into the aisle, which presents a less predictable and more volatile secondary impact environment to the occupant.

Workstation tables were also indicated as the cause of thoracic and abdominal blunt trauma during collisions and derailments in Intercession City, FL [7], Burbank, CA [8], and Glendale, CA [9]. In the Intercession City, FL, collision, passengers and crew suffered rib, sternum, and hip fractures, neck injuries, and facial injuries from impacts with dining tables. In the Burbank, CA, derailment, one occupant was rendered paraplegic after impacting a workstation table. Preliminary results from the Glendale, CA, collision and derailment indicate that at least two serious and several minor injuries resulted from workstation table impacts.

\section{Analyze the Problem}

The second step in the development process consists of a preliminary analysis to assist in understanding the problem. Simple calculations and more detailed computer simulations determine the boundaries of the problem. For instance, such analyses of the Placentia, CA, collision have confirmed that the loads and accelerations imparted on the occupants exceed the human tolerance to thoracic and abdominal injury. Loss of compartmentalization is possible if the table attachments fail.

An important factor is the role of the biomechanical impact response, as well as injury tolerance, of the human thorax and abdomen. During a collision, an occupant seated at a workstation table is likely to strike the table at the upper abdomen level, a region centered on the T11 thoracic vertebrae [10]. Research that directly addresses this area of the abdomen is scarce. Most of the work has focused on lap belt submarining loads and lateral impacts in the automotive industry. Both of these loading events are unlikely to occur in a workstation table impact. A better understanding is needed to relate the loading conditions specific to workstation table impacts to the risk of thoracic and abdominal injury. 
Three indicators are commonly used to assess the risk of abdominal injury: compression, rate of compression, and force. Anthropomorphic test devices (ATDs) that have a biofidelic abdominal impact response must be used to measure abdominal compression. Since there are no widely accepted maximum injury tolerance levels, these measures of the abdominal response to the impact with the conventional and improved workstation tables will be compared. However, for the purpose of this effort, the following suggested tolerance levels will be used.

The maximum acceptable abdominal compression is $75 \mathrm{~mm}$, or a compression ratio of roughly $40 \%$ for a $50^{\text {th }}$ percentile male occupant. This corresponds to an AIS 4+ injury probability of 0.1 [11]. The maximum acceptable rate of compression will be assessed by the viscous criterion, which accounts for both the rate of compression and the compression ratio. The suggested abdominal viscous criterion tolerance level is $1.98 \mathrm{~m} / \mathrm{s}$ [12], while the suggested viscous criterion tolerance level for the chest is $1.0 \mathrm{~m} / \mathrm{s}$. The latter corresponds to an AIS 3+ injury probability of 0.25 [13]. Since the table impact is likely to occur in the upper abdominal region, the maximum acceptable viscous criterion for this effort will be 1.5 $\mathrm{m} / \mathrm{s}$, using compression and velocity measured at the level of table impact. The suggested upper abdominal force tolerance level is $6.73 \mathrm{kN}$ [12]. The maximum acceptable upper abdominal force in this effort will be $6.5 \mathrm{kN}$.

An important aspect of analyzing the problem is considering the occupant environment in which an improved workstation table will be implemented. A definition of the occupant environment includes both the physical arrangement of the interior structures and the acceleration that the occupants are subjected to. The environment that defines the design of an improved table is drawn from three sources. The evidence from the historical review and the field study, standards and recommended practices for interior structures, and an estimation of the acceleration environment from the upcoming CEM train-to-train full-scale test will be taken into consideration. The physical arrangement of the interior structures will consist of the facing-seat arrangement that is common on Bombardier multi-level passenger cars, primarily because data exist for this seating arrangement [14]. This seating arrangement, shown in Figure 2, has a seat pitch of 65 inches.

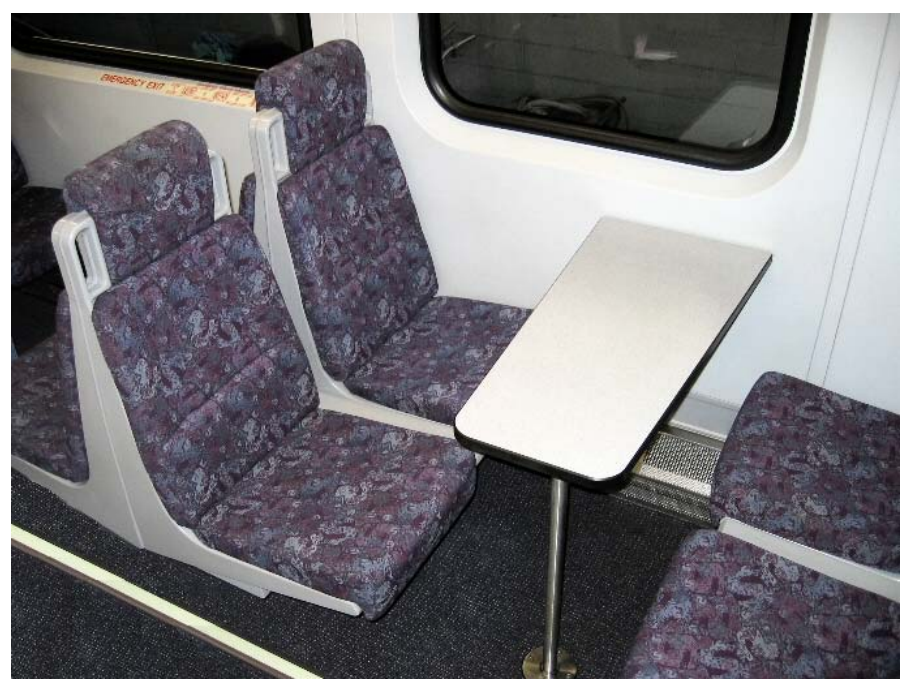

Figure 2. Facing-seat arrangement with intervening workstation table.

One way to determine the severity of the acceleration pulse subjected to the occupants is to examine the associated secondary impact velocity (SIV). The SIV defines the velocity at which, under a defined acceleration pulse, an occupant will impact an interior structure that is a certain distance from the initial position of the occupant. SIV has been demonstrated to be a good predictor of overall injury risk [1].

Figure 3 shows four SIV curves. The first curve shows the SIV associated with an 8G, 250-millisecond triangular acceleration pulse. This pulse is typically used in the qualification of rail passenger seating arrangements [15]. The second curve shows the SIV associated with the estimated acceleration pulse in the lead section of the cab car during the Placentia, CA, collision. This acceleration pulse was determined from a collision dynamics model based on the information from the investigation [2]. The third curve shows the SIV associated with the predicted acceleration of the cab car in the CEM train-to-train full-scale test [16]. The final curve, for sake of reference, is the SIV associated with the acceleration measured from the lead car of the CEM two-car full-scale test [4]. This curve indicates the severity of the test of existing equipment that will be described in the following section. 


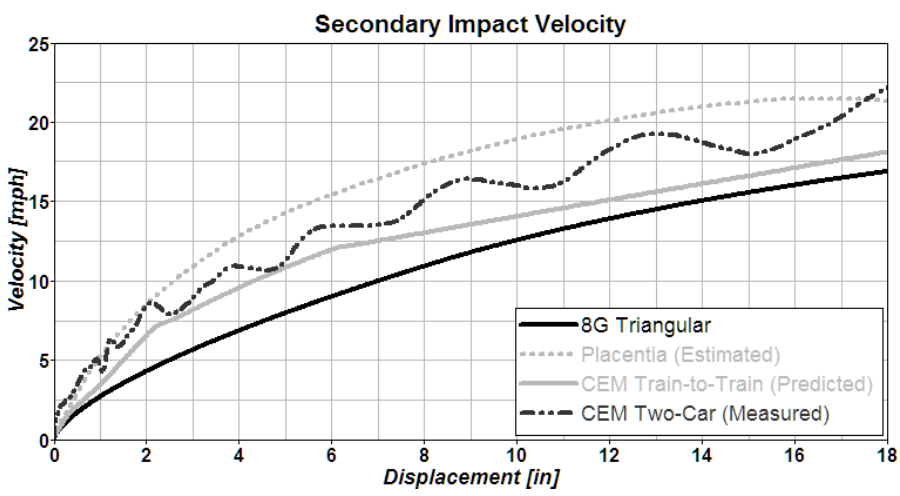

Figure 3. SIVs of four occupant environments.

There are two strategies that will be incorporated into the workstation table design to decrease the severity of the secondary impact. The first is to decrease the distance traveled by the occupant before engaging the table. The current workstation table design allows the occupant up to 12 inches before impact. From Figure 3, this relates to SIVs of between 14 and $20 \mathrm{mph}$, depending on the collision scenario. If this distance is decreased to 8 inches, the associated SIVs are reduced to 11 to $17 \mathrm{mph}$, which subsequently reduces the injury risk. Either decreasing the seat pitch or increasing the overall width of the table can decrease the distance traveled. The latter method is preferred, as decreasing the seat pitch would compromise legroom and hinder ingress and egress.

The second strategy that will be incorporated to decrease the severity of secondary impact is a method of absorbing energy. If an occupant is traveling at between 11 and $17 \mathrm{mph}$ upon impact with a rigid table edge, the force necessary to arrest the motion of the occupant is extremely high. However, an energy-absorbing table can dissipate the kinetic energy of the occupant over a longer time interval, thus decreasing the peak force necessary to arrest the motion of the occupant.

In order to get an idea of the energy absorption requirements of an improved workstation table, consider the case of a $50^{\text {th }}$ percentile male occupant seated such that the upper abdomen is 10 inches away from the table. Under an 8G, 250-millisecond triangular acceleration pulse, the occupant will be traveling towards the table at $12.5 \mathrm{mph}$ upon impact (assuming that the interaction between the occupant and the launch seat is negligible). If the entire mass of the occupant comes to rest at the same time, the equivalent of roughly $900 \mathrm{ft}-$ lbf of kinetic energy is dissipated. This estimate is overly conservative, as the upper and lower extremities of the occupant tend to maintain their forward velocity after the abdomen has come to rest. If the effective mass of the occupant during an abdominal impact is assumed to be two thirds of the total mass, an effective table must absorb $600 \mathrm{ft}$ lbf of energy. In the more severe case of the CEM train-to-train full-scale test, the SIV of the occupant would be $14 \mathrm{mph}$, which indicates a necessity of the table to absorb $750 \mathrm{ft}-\mathrm{lbf}$.

Before conducting a full-scale test of the baseline case, a multi-body dynamic model was implemented using the
MADYMO 6.1 solver [17]. This model consisted of a Test Device for Human Occupant Restraint (THOR) ATD seated in a facing-seat arrangement with an intervening workstation table. A simulation was run using the predicted acceleration from the CEM two-car full-scale test as the input. This simulation was used to determine the proper instrumentation for the test, as well as the range of expected outcomes [5].

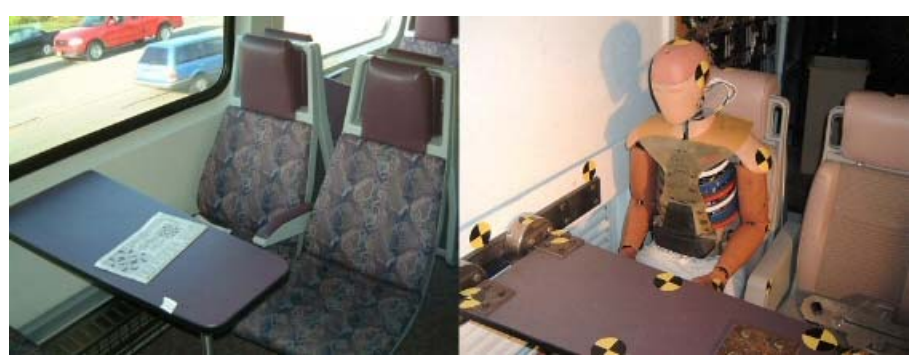

Figure 4. The full-scale test of the baseline table design, right, closely resembles the actual seating arrangement, left.

\section{Test the Baseline Design}

Step three, testing of existing equipment, is conducted to collect quantitative information on the baseline table design. This information forms the basis of a comparison of the measured loads and accelerations imparted on the occupants during testing. On the CEM full-scale two-car impact test conducted on February 26, 2004, two experiments involved the facing-seats with intervening workstation table arrangements similar to those in the Placentia collision (see Figure 4). The main difference was that the mounting points were strengthened in order to allow measurement of the peak loads imparted on the table before failure. These experiments implemented advanced ATDs to measure the abdominal response to the table impact. This test confirmed the need for crashworthiness improvements in the design of the workstation table [5]. Additionally, these test results serve as a point of reference to evaluate the performance of an improved design.

\section{Refine the Simulation}

The data collected during the full-scale test are used to refine the preliminary analysis, the fourth step in the process. Refined computer simulations can assist in the development and evaluation of potential improvements. For instance, analysis shows that a table with an energy-absorbing edge can reduce the thoracic and abdominal injury risk to the occupants by as much as $50 \%$ [5].

While the pre-test MADYMO simulation using the THOR ATD showed good correlation with the test results, some modifications were necessary. The refined simulation was adjusted based on the data collected during the test to account for the actual car body acceleration, initial position of the occupant, and contact parameters between the occupant and the seating arrangement. Additionally, a model of the Hybrid III Railway Safety (Hybrid 3RS) ATD was created by making minor modifications to the standard Hybrid III model. A 
simulation of the Hybrid 3RS experiment was also implemented and refined based on the test results [5]. Figure 5 shows a comparison of the full-scale test to the MADYMO simulation for both the THOR and Hybrid 3RS.
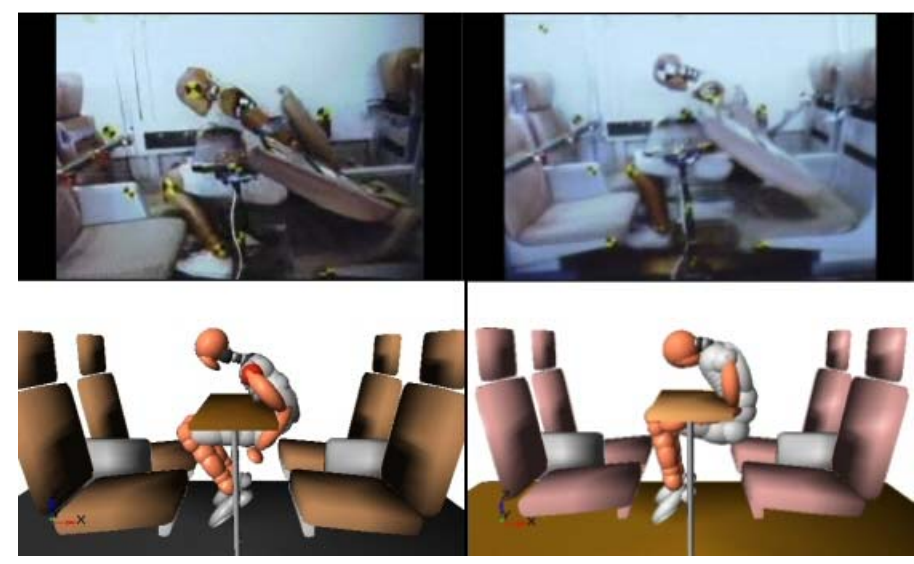

Figure 5. A comparison of the full-scale test (top) to the MADYMO simulation (bottom) of the workstation table experiments of the THOR ATD (left) and the Hybrid 3RS ATD (right).

\section{$\underline{\text { Develop a Detailed Design }}$}

\section{Design Requirements}

The fifth step in development process has several components. The first is the definition of the requirements that such a design must fulfill. These design requirements are primarily determined based on the information gathered in the previous steps. The primary design requirement for this effort is crashworthiness performance. With respect to a workstation table, crashworthiness performance is defined by the ability of the table to both compartmentalize the occupants and minimize the thoracic and abdominal injury risk. In addition to the crashworthiness performance requirements, the table design must also meet requirements to address the geometry of the table and the functionality of the table under service loads. Finally, the table must meet all of the applicable federal regulations, standards, and recommended practices.

\section{Crashworthiness Performance}

There are four crashworthiness performance design requirements that an improved workstation table must meet. The first is that the table must compartmentalize the occupants seated facing the table during a collision. It has been shown that compartmentalization is an effective occupant protection strategy [18]. The primary benefit of compartmentalization is a reduction of SIVs. As shown in Figure 3, the farther an occupant travels before impacting interior structures, the higher the associated SIV, and the higher the associated injury risk. Under a strictly longitudinal acceleration pulse, an occupant will travel 10 to 12 inches before impact with the table. However, if the table fails, the occupant could travel 4 feet before impact with the facing seats or even another occupant. This would occur at a higher velocity (up to the closing speed of the colliding vehicles) than the initial impact with the table, thus the injury risk would be exacerbated.

Furthermore, compartmentalization increases the predictability of secondary impacts. If the occupants are contained within a set envelope during a collision, it is possible to predict the surfaces that will be impacted by the occupant, and design these surfaces to cushion the impact. In the case of the workstation table, the geometric limitations of the seating arrangement enable a relatively certain prediction of the initial position of the occupant before impact. However, if the table were to fail, the subsequent motion of the occupants would be difficult to predict. Thus, the attachments of the table to the car body must not fail during impact.

The second crashworthiness performance design requirement is that the impacted edge of the table limits and distributes the load imparted on the abdomen of the occupant. In order to retain its functionality, the height of the table requires that the edge of the table aligns with the abdomen of a seated occupant. The abdomen is a vulnerable region of the body, as there is no bony structure to prevent damage to internal organs during impact. An improved table must limit the load imparted on the abdomen in order to reduce the risk of injury.

Along with limiting the abdominal load, the table must absorb energy during the impact. Due to the limited space available to do so, the energy-absorbing element must be efficient. The strategy that will be employed entails a forcedisplacement characteristic that quickly rises to the maximum acceptable load level and then remains at that plateau for the remainder of the displacement of the table. This displacement can come about though motion of the tabletop or crushing of the table edge, as will be discussed in the design concept section.

A parametric analysis was designed to determine the appropriate force-displacement characteristic of the table. This analysis exercised the refined MADYMO simulation, including the THOR ATD model subjected to an 8g, 250-millisecond triangular acceleration pulse. This simulation was exercised using 15 different table force-displacement characteristics. These characteristics were identical in shape, as the force level quickly rose up to a plateau after 1 centimeter of displacement. The plateau was varied from $4 \mathrm{kN}$ to $8 \mathrm{kN}$, with an increased density between $5 \mathrm{kN}$ and $6 \mathrm{kN}$, as this region appeared to be the most promising. The results of this parametric analysis indicated that a plateau force of $5.5 \mathrm{kN}$ was optimal in that the loads imparted on the occupant were minimized while the conditions of the table deformation were met. Using this forcedisplacement characteristic, all of the measurements are well within the maximum acceptable injury tolerance levels, as shown in Table 1. 
Table 1. Results from MADYMO simulation of the optimal table force-displacement characteristic.

\begin{tabular}{|l|c|c|}
\hline \multicolumn{1}{|c|}{ Injury Criteria } & $\begin{array}{c}\text { Maximum } \\
\text { Tolerance }\end{array}$ & $\begin{array}{c}\text { Frangible Table } \\
\text { 5.5kN plateau }\end{array}$ \\
\hline Abdominal Load & $6.5 \mathrm{kN}$ & $5.9 \mathrm{kN}$ \\
\hline Abdominal Compression & $75 \mathrm{~mm}$ & $48.8 \mathrm{~mm}$ \\
\hline Abdominal V*C & $1.5 \mathrm{~m} / \mathrm{s}$ & $0.34 \mathrm{~m} / \mathrm{s}$ \\
\hline Chest G & $60 \mathrm{~g}$ & $23.2 \mathrm{~g}$ \\
\hline HIC15 & 700 & 49.6 \\
\hline
\end{tabular}

During an impact with a narrow table edge, a concentrated force can cause severe damage to abdominal organs. In order to prevent this concentrated force, the edge of the table must be thicker and distribute the load over a larger area. If possible, the table should be thick enough to engage the rib cage of the occupant, which can resist a higher load than the abdomen alone.

The third crashworthiness performance design requirement is that the maximum acceptable injury tolerance levels are not exceeded during an 8g, 250-millisecond triangular acceleration pulse sled test using two $50^{\text {th }}$ percentile male ATDs. This is important because it must be demonstrated that the table is successful in reducing the thoracic and abdominal injury risk without increasing risk in another area. The injury tolerance levels that will be considered include the head, neck, chest, abdomen, and femurs. Table 2 shows the maximum acceptable injury tolerance levels that will be used in the design of an improved workstation table.

Table 2. Maximum acceptable injury tolerance levels for the performance of an improved crashworthiness performance table.

\begin{tabular}{|l|c|l|}
\hline \multicolumn{1}{|c|}{ Injury Criteria } & $\begin{array}{c}\text { Maximum } \\
\text { Tolerance }\end{array}$ & \multicolumn{1}{c|}{ Units } \\
\hline HIC15 & 700 & \\
\hline Nij & 1.0 & \\
\hline Neck Tension & 4,170 & $\mathrm{~N}$ \\
\hline Chest Acceleration & 60 & $\mathrm{G}$ \\
\hline Chest Compression & 67 & $\mathrm{~mm}$ \\
\hline Chest $\mathrm{V}^{*} \mathrm{C}$ & 1.0 & $\mathrm{~m} / \mathrm{s}$ \\
\hline Abdominal Compression & 75 & $\mathrm{~mm}$ \\
\hline Abdominal Force & 6,500 & $\mathrm{~N}$ \\
\hline Abdominal $\mathrm{V}^{*} \mathrm{C}$ & 1.5 & $\mathrm{~m} / \mathrm{s}$ \\
\hline
\end{tabular}

The final crashworthiness performance design requirement is that the table does not hamper the egress of passengers. In the event of an emergency evacuation of the passenger car, the occupants seated at tables must be able to leave their seats and exit the car without undue delay. If the improved table design includes a mechanism for controlled deformation, the table must not impede the egress of occupants on either side of the table either before or after the mechanism is exercised. This is important because occupants must not be trapped on the passenger cars in the event of a fire or other emergency situations.

\section{Geometry}

The requirements for the geometry of the improved workstation table are dictated by the passenger vehicle on which they will be installed. For this effort, it will be assumed that the table will be installed on a Bombardier multi-level cab or coach car between facing seats with a 65-inch seat pitch. Within the facing-seat arrangement, the table or its attachments must not obstruct the space of any of the four possible occupants, nor shall it impede their ingress or egress.

In order to meet the crashworthiness requirements, certain geometric features of the tabletop are necessary. First of all, to ensure compartmentalization, the tabletop must extend completely from the wall to the aisle. If this is not the case, the occupant of the aisle-side seat may be thrown into and across the aisle during a collision or derailment, which could lead to a more severe secondary impact. It is important to protect the window-side and aisle-side occupants equally.

Second, to distribute the load on the abdomen during an impact over as large an area as possible, the table shall be as thick as space allows. The thickness of the table is limited by the maximum height of the table and the required space beneath the table for the legs of the occupants. If the table is too high, it will lose its functionality of as a table. If the table is too low or too thick, it will impede occupant ingress, egress, and overall comfort while seated at the table. The minimum thickness of an improved workstation table will be 2 inches.

Third, to decrease the overall injury risk to the occupants, the table should be as wide as space allows. As shown in Figure 3, the smaller the distance traveled by the occupants before impacting the table, the smaller the SIV, thus the lower the injury risk. A wide table will leave a smaller gap between the occupant and the table, allowing a smaller distance to be traveled before impact during a collision or derailment. This will also improve compartmentalization, as the decreased time of free flight will decrease the contribution of lateral and vertical accelerations on the occupant. As with the table thickness, there is a tradeoff between the width of the table and the facility of ingress and egress.

A preliminary assessment of the geometry requirements of the workstation table is shown in Figure 6 and Figure 7. Figure 6 depicts a top view of the table, along with the minimum and maximum depth, width, thickness, and height. Figure 7 depicts a side view of the seating arrangement, including a representation of a Hybrid III $50^{\text {th }}$ percentile male occupant. The shaded areas depict the occupant space that the improved table must not obstruct. 


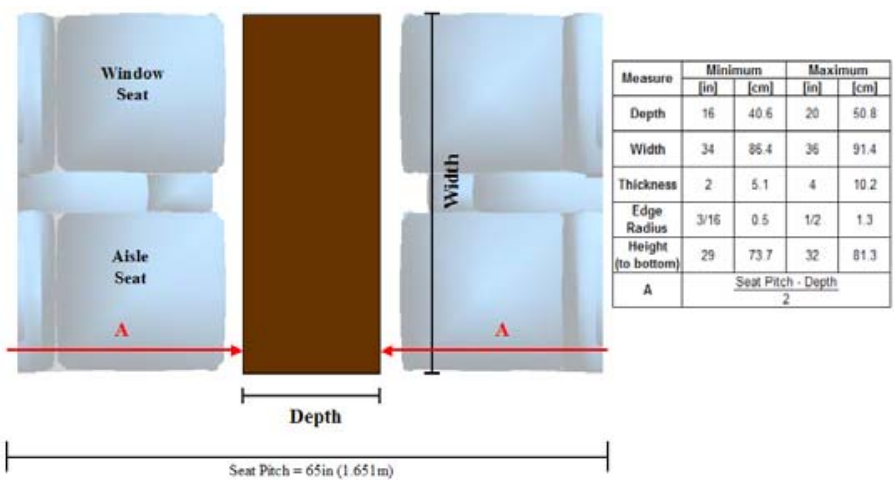

Figure 6. Top view of the workstation table, indicating the required geometry.

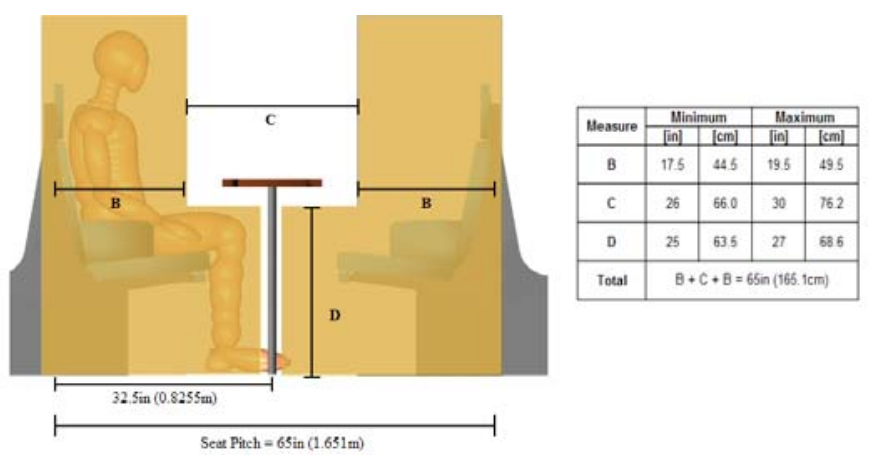

Figure 7. Side view of the facing-seat arrangement with intervening workstation table, indicating the necessary occupant volume.

\section{Functionality}

An important aspect of the design of an improved workstation table is that it retains the functionality of a table. From conversations with passengers and operating authorities, as well as observation, it is apparent that the seats with tables are the most sought-after seats on passenger rail cars. Passengers enjoy the convenience of a table in front of them to rest their coffee, magazine, notepad, or laptop computer on and to get some work done during their commute. Thus, an improved table must retain this functionality. Most of the functionality of a table lies in its geometry, as discussed above. It is also important to ensure that the table can retain such functionality over its service lifetime.

While the crashworthiness requirements detail the loads that the table must withstand under collision impact loads, it is necessary to consider the loads that the table will see in service. These loads are smaller than the collision loads, though applied on a daily basis. If the improved table design includes any deformable mechanisms, such mechanisms must not be damaged under non-collision loads. Also, the collision loads are primarily in the longitudinal direction, whereas the services loads are most severe in the vertical direction.

Two measures of service loads, one horizontal and one vertical, were chosen in order to ensure the operational strength of the table. The horizontal service load requirement states that neither the table edge nor the table attachments shall experience permanent deformation under a 500lbf load at any location (distributed over a finite area) on the table edge, applied in the longitudinal direction. This requirement ensures that the energy-absorbing qualities of the table are not damaged by use and abuse during normal service. The vertical service requirements states that neither the table edge nor the table attachments shall experience permanent deformation under a $350 \mathrm{lbf}$ load in a vertical direction at any location (distributed over a finite area) on the top of the table. This requirement ensures that the tabletop will remain intact under the possible scenario of two 175lbf occupants sitting or standing on the edge of the table.

The final functionality requirement is that maintenance of the table shall be minimized. The service life of the tables shall reflect the average time interval between interior refurbishment of a passenger rail car, which is on average 8 to 12 years. The tables shall not require regular inspection, testing, or adjustments during the service life. Surfaces shall be scratchresistant, smooth, and wipe clean with typical cleaning products. Materials that require painting for a finish are undesirable, as they may chip and require touch up or repainting on a scheduled basis. If the table design includes any mechanisms to improve crashworthiness performance, such mechanisms shall not be damaged under normal use. These mechanisms shall be inaccessible to the passengers, while they shall be accessible for any required maintenance.

\section{Regulations, Standards, and Recommended Practices}

A requirement of the improved workstation table design shall meet the same federal regulations, as well as American Public Transportation Association (APTA) standards, subject to interior passenger rail structures. Specifically, the table design must conform to Code of Federal Regulations (CFR) Title 49, Part 238, Sections 103 and 233, "Fire Safety" and "Interior Fittings and Surfaces," respectively [15],[19]. The relevant APTA standards are found in SS-C\&S-016-99, Rev. 1, "Standard for Row-to-row Seating in Commuter Rail Cars," [20].

As the improved workstation table design is a collaborative effort between the United States and the United Kingdom, the design requirements state that the table shall conform to the United Kingdom's Association of Train Operating Companies (ATOC) Vehicle Standard AV/ST9001.10 [21]. This is only a requirement for this proof-of-concept design, and is not a U.S. regulatory requirement.

\section{Concept Generation and Evaluation}

The next component in developing the detailed design of an improved workstation table is to generate and evaluate an array of concepts that are likely to fulfill the requirements. The design concepts were narrowed down into four categories based on the occupant protection method: inflatable restraints or airbags, pivoting table, energy absorbing attachments, and crushable table edge. These four categories were further 
divided into subcategories of greater detail. A total of 28 concepts were evaluated against a set of criteria drawn from the design requirements.

\section{Inflatable Restraints/Airbags}

Research in the automotive industry has demonstrated that the use of airbags can reduce the injury risk to occupants during a collision [10]. One design concept was to incorporate this occupant protection strategy into the workstation table. Several methods of implementation are possible. An airbag could be deployed at the edge of the table itself, which would distribute the load over the entire thorax of the occupant. This could be accompanied by an airbag below the table that acts as a knee bolster to limit the motion of the knees and femurs of the occupant, reducing velocity before the abdomen engages the table. The airbag concept excels in the ability to compartmentalize occupants, distribute the load over a large area, and protect the aisle-side and window-side occupants equally. However, the airbag has several disadvantages. The most harmful disadvantage is the sensitivity to the initial position of the occupants. If occupants are leaning against the table edge as the airbag inflates, they could potentially suffer a more severe injury than if the airbags were not present. Also, the use of airbags would require the use of active control, which can be expensive.

\section{Pivoting Table}

A pivoting table would have a rotational joint that runs laterally down the center of the table with a table edge attached to either side. This edge, when impacted, would rotate either upwards or downwards while absorbing energy over its range of motion. The method of energy absorption could be hydraulic, a brake/clutch system, or a rotational spring, each with its own complexity and cost concerns. The direction of table edge rotation has several concerns as well. If the table rotates downwards, it could promote a head impact with the table, as well as trapping occupants after a collision. If the table rotates upwards, there is the potential of the occupant overriding the system and impacting interior structures or occupant farther forward in the car. Thus, the compartmentalization and egress concerns of a pivoting table design prevent its feasibility.

\section{Energy-Absorbing Attachments}

The use of energy-absorbing attachments is the most costeffective concept presented. In this concept, the tabletop itself would remain rigid. However, the attachment of the tabletop to the car body would be the energy-absorbing feature. The tabletop could slide along channels mounted to either a pedestal underneath the table or a channel attached to the wall. As the table slides along the channel during an impact, one of several methods of energy absorption would slow the motion of the table. This could be accomplished by using a shock absorber, a crushable element, or the calculated plastic deformation of a known material. The benefits of this concept are its ability to meet the static load requirements, since the tabletop itself need not be modified; a relatively low cost and ease of implementation in a wide variety of interior configurations; and the lack of active controls. However, this table design concept lacks the energy absorption efficiency of other designs, and may not equally protect the aisle-side and window-side occupants. Also, if the table slides too far relative to the car body, there is a risk of trapping or even impacting the occupants of the facing seats.

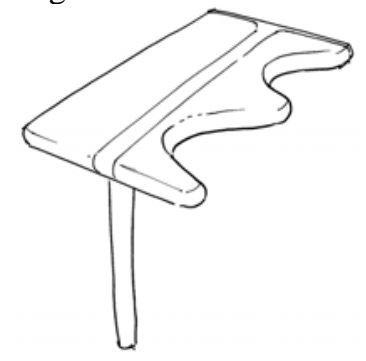

Figure 8. Illustration of the crushable table edge concept, indicating the deformation of the edge during the impact of two occupants.

\section{Crushable Table Edge}

The concept of a crushable table edge shows the highest potential for a successful occupant protection strategy. This concept employs a center frame that is rigidly attached to the car body either by a pedestal leg near the aisle and a wall attachment or a C-shaped frame that attaches along the wall and under the floor. The tabletop consists of a crushable material and is divided into two sides, which are attached to the center frame, as shown in Figure 8. This crushable material could be foam, hollow tubes, or honeycomb. The benefits of this concept are its ability to compartmentalize occupants, distribute and limit the abdominal load, efficiently absorb energy, preserve of occupant volume, and protect the aisle-side and window-side occupants equally. This concept also benefits from the lack of active controls, ease of manufacture, and minimal required maintenance. One concern is the ability of a crushable material to withstand the expected service loads; however, this can be addressed with strategic reinforcement of the material.

\section{Preliminary Design}

During the concept evaluation phase of this effort, the crushable table edge was chosen as the most likely concept to meet the design requirements. The details of this concept were further developed into a preliminary design, shown in Figure 9. 


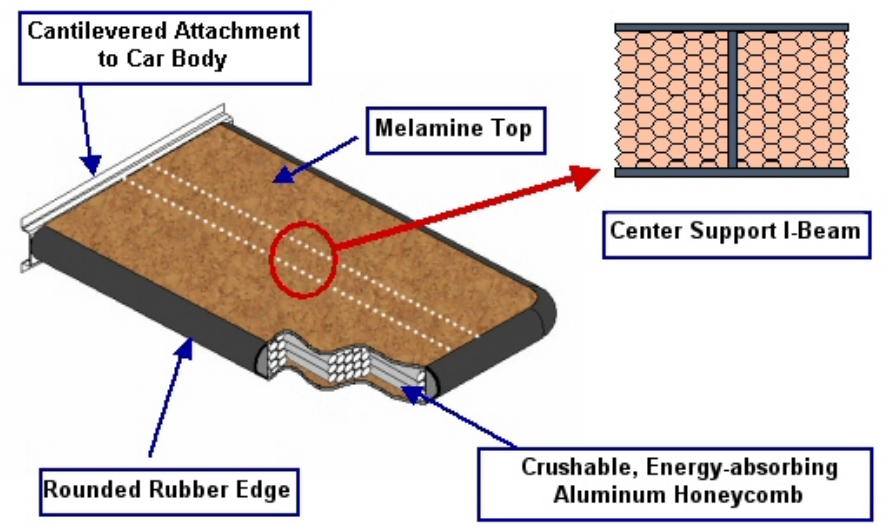

Figure 9. Preliminary workstation table design to be developed, fabricated, and tested.

This preliminary design builds from a center support Ibeam, which is cantilevered from the car wall, that and extends laterally from the wall to the aisle. The table edge is constructed of a crushable, energy-absorbing aluminum honeycomb. A layer of melamine forms the tabletop, and a rounded rubber edge spans the perimeter of the table.

The center support I-beam is designed to remain attached under the impact loads from two occupants during a collision, ensuring that the occupants remain compartmentalized. It also supports the table under service loads. The added benefit of an I-beam over a box section for the center support is the increased energy absorption potential of the table edge, since the crushed material can build up between the flanges of the Ibeam. This table design does not employ a pedestal or leg; however, a small angled support may be necessary at the wall attachment.

The crushable aluminum honeycomb that makes up the table edge is oriented so that cells are oriented laterally with respect to the passenger car. This allows for the table edge to achieve the target force-crush characteristic while remaining stiff enough to meet the service load requirements. The table edge is at least three inches thick in order to distribute the load over a large area. This table edge arrangement provides the same force-crush characteristic for the aisle and window occupants.

The melamine tabletop provides a rigid surface to preserve the functionality of the table. Connections between the tabletop and the aluminum honeycomb edge provide additional support in meeting the service load requirements. During impact, the melamine top is designed to break away in such a manner that it will not adversely affect the force-crush characteristic, and it will not become a projectile. The rubber edge distributes the load from the melamine top and the aluminum honeycomb to provide a benign impact surface to the occupants during a collision.

Preliminary analyses indicate that this preliminary table design can achieve the necessary crashworthiness performance, geometry, and functionality requirements. Further analyses, including a detailed crush simulation and an occupant response simulation, will assist in finalizing the design details before fabrication.

\section{FUTURE WORK}

After the improved workstation table design is finalized, four such tables will be fabricated. The first table will be included in a quasi-static test to ensure that the desired forcecrush characteristic of the table edge is met and no unforeseen failure modes occur. The measured force-crush characteristic will be used to further refine a finite element crush analysis. Using this data, a multi-body dynamic simulation will be run to predict the occupant response under an 8g, 250-millisecond triangular acceleration pulse. This simulation will be used to determine the instrumentation scheme for a full-scale sled test of the second improved workstation table. The remaining two workstation tables will be included on the CEM train-to-train full-scale impact test. Two experiments are currently planned, one using the THOR ATD and one using the Hybrid 3RS ATD [16]. The objective of these experiments is to demonstrate the crashworthiness performance of the improved workstation table. The measurements collected during the CEM train-totrain test will be compared to those collected in the CEM twocar test.

\section{CONCLUSION}

During collisions and derailments of passenger rail equipment, workstation tables in facing-seat arrangements have contributed to severe, and in some cases fatal, thoracic and abdominal injuries. Analysis has shown that an improved workstation table can significantly reduce this injury risk. Work is currently underway on the development of a table that is able to compartmentalize the occupants while limiting and distributing the loads imparted on the abdomen. The previous work completed in this task includes a review of historical accidents and a field study of occupant injury, an analysis including computer simulations of the occupant response to table impact, a full-scale test of the current table design, and the subsequent refinement of the computer simulations following the test. The refined computer simulations have been used to assist in the development of crashworthiness performance requirements for the improved table.

Design requirements for the crashworthiness performance, geometry, and functionality of an improved table are currently in place. Design concepts have been generated and evaluated based on their ability to fulfill the design requirements. The highest-ranking design concept involves a crushable table edge mounted to a rigid frame. This crushable edge, constructed of foam or honeycomb, will provide the desired force-crush characteristic to reduce the risk of thoracic and abdominal injury. This design will be fabricated and tested to demonstrate the improved crashworthiness performance.

\section{ACKNOWLEDGMENTS}

The research discussed in this paper was performed as part of the Equipment Safety Research Program sponsored by the 
Office of Research and Development of the Federal Railroad Administration. The authors would like to thank Dr. Tom Tsai, Program Manager, and Ms. Claire Orth, Division Chief, Equipment and Operating Practices Research Division, Office of Research and Development, Federal Railroad Administration, for their support.

The authors would like to thank Grady Cothen, Acting Associate Administrator for Safety Enforcement, and Jo Strang, Deputy Associate Administrator for Railroad Development, for their efforts to coordinate the accident investigations with the National Transportation Safety Board. The authors would also like to thank Gunars Spons, Federal Railroad Administration Resident Manager at the Transportation Technology Center, for managing the full-scale test effort, and Mark Haffner, THOR Program Manager, National Highway Transportation Safety Administration, for the use of the THOR ATD.

\section{REFERENCES}

[1] Tyrell, D.C., Severson, K.J., Marquis, B.J., "Crashworthiness of Passenger Trains," U.S. Department of Transportation, DOT/FRA/ORD-97/10, 1998.

[2] Parent, D., Tyrell, D., Perlman, A.B., "Crashworthiness Analysis of the Placentia, CA Rail Collision,” International Journal of Crashworthiness, Volume 9, Issue 5, pp. 527-534, March 8, 2004.

[3] National Transportation Safety Board, "Collision of Burlington Northern Santa Fe Freight Train With Metrolink Passenger Train, Placentia, California, April 23, 2002," Railroad Accident Report NTSB/RAR-03-04, adopted on 10/7/2003.

[4] Jacobsen, K., Tyrell, D., Perlman, A.B., "Impact Tests of Crash Energy Management Passenger Rail Cars: Analysis and Structural Measurements,” American Society of Mechanical Engineers, Paper No. IMECE2004-61252, November 2004.

[5] Parent, D., Tyrell, D., Perlman, A.B., Matthews, P., "Evaluating Abdominal Injury in Workstation Table Impacts," Transportation Research Board 84th Annual Meeting, Paper No. 05-1348, Washington, DC, January 9-13, 2005.

[6] Severson, K., Tyrell, D., Rancatore, R., Perlman, A.B., "Crashworthiness Requirements for Commuter Rail Passenger Seats,” American Society of Mechanical Engineers, Paper No. IMECE2005-82643, November 2005.

[7] National Transportation Safety Board, "Collision of Amtrak Train No. 88 with Rountree Transport and Rigging, Inc., Vehicle on CSX Transportation, Inc., Railroad Near Intercession City, Florida, November 30, 1993,” Railroad Accident Report NTSB/HAR-95/01, adopted on 5/16/1995.

[8] National Transportation Safety Board, "Collision Between Metrolink Train 210 and Ford Crew Cab, Stake Bed Truck at Highway-Rail Grade Crossing, Burbank, California, January 6, 2003," Highway Accident Report NTSB/HAR-03/04, adopted on $12 / 2 / 2003$.
[9] Smith, G., Zahniser, D., Krasnowski, M., “11 Killed in 3Train Wreck Near L.A.," The San Diego Union-Tribune, January 27, 2005.

[10] Rouhana, S.W., Hardy, W.N., and Schneider, L.W., "Abdominal Impact Response to Rigid-Bar, Seatbelt, and Airbag Loading,” Stapp Car Crash Journal, Volume 45, November 2001, pp. 1-32.

[11] Rouhana, S.W., Viano, D.C., Jedrzejczak, E.A., and McCleary, J.D., “Assessing Submarining and Abdominal Injury Risk in the Hybrid III Family of Dummies,” Proc. $33^{\text {rd }}$ Stapp Car Crash Conference, pp. 257-279, SAE Technical Paper No. 892440, October 1989.

[12] Wallace, W.A. and Srinivasan, S.C.M., "Rail Passenger \& Crew Survivability Studies - Part 2,” November 2002.

[13] Viano, D.C., and Lau, I.V., "A Viscous Tolerance Criterion for Soft Tissue Injury Assessment," Journal of Biomechanics, Vol. 21, p. 387, 1988.

[14] VanIngen-Dunn, C., "Commuter Rail Seat Testing and Analysis of Facing Seats," DOT/FRA/ORD-02/XX, U.S. Department of Transportation, Washington, DC, June 2002.

[15] Code of Federal Regulation, Title 49, Part 238, Section 233: Interior fittings and surfaces.

[16] Tyrell, D., Jacobsen, K., Parent, D., Perlman, A.B., "Preparations for a Train-to-Train Impact Test of Crash-Energy Management Passenger Rail Equipment,” American Society of Mechanical Engineers, Paper No. RTD2005-70045, March 2005.

[17] MADYMO, Version 6.1, TNO Automotive, Delft, The Netherlands.

[18] Tyrell, D.C., Severson, K.J., Marquis, B.J., “Analysis of Occupant Protection Strategies in Train Collisions,” ASME International Mechanical Engineering Congress and Exposition, AMD-Vol. 210, BED-Vol. 30, pp. 539-557, 1995.

[19] Code of Federal Regulation, Title 49, Part 238, Section 103: Fire safety.

[20] APTA SS-C\&S-016-99, Rev. 1, Standard for Row-toRow Seating in Commuter Rail Cars, The American Public Transportation Association, Washington, D.C.

[21] ATOC Vehicles Standard AV/ST9001, "Vehicle Interior Crashworthiness,” Part B, Section 10, February 2002. 